\title{
Culturemas em contraste: idiomatismos do português brasileiro e europeu
}

Culturemes in contrast: idioms from Brazilian and European Portuguese

\begin{abstract}
Claudia Xatara*
Mariele Seco**

RESUMO: No presente trabalho estudamos as expressões idiomáticas equivalentes em português brasileiro e em português europeu e suas redes sinonímicas com o objetivo de analisar os principais culturemas que, possivelmente, deram origem a tais expressões e ainda verificar se a existência de diferentes culturemas pode, realmente, acarretar diferenças na formulação fraseológica de idiomatismos. O corpus do trabalho compôs-se das entradas em português brasileiro e seus respectivos equivalentes em português europeu do Dicionário de expressões idiomáticas português do Brasil e de Portugal - francês da França, da Bélgica e do Canadá (XATARA, 2013). Por meio de um levantamento dos elementos históricos, religiosos e culturais mais significativos apresentados pelas duas variantes da língua portuguesa, pudemos detectar e apresentar os

ABSTRACT: In this paper we study idiomatic expressions that are equivalents in Brazilian Portuguese and European Portuguese and their synonymic relations. We aim to analyze the principal culturemes that possibly originated such expressions and to verify if the existence of different culturemes can actually induce differences in the phraseological formulation of idioms. The corpus will consist of entries in Brazilian Portuguese and their respective equivalents in the "Dicionário de expressões idiomáticas portúguês do Brasil e de Portugal - francês da França, da Bélgica e do Canadá" (XATARA, 2013). Through the study of the most significant historical, religious and cultural elements presented by the two variants of Portuguese, we were able to determine and present the most relevant culturemes in the expressions and their equivalents.
\end{abstract} culturemas mais relevantes que constam em tais expressões e seus equivalentes.

PALAVRAS-CHAVE: Idiomatismo. Fraseologia. Culturema. Equivalência.
KEYWORDS: Idiom. Phraseology. Cultureme. Equivalence.

\section{Introdução}

Estudamos as expressões idiomáticas (EIs) como unidades fraseológicas (UFs) representadas por lexias complexas conotativas, abundantemente utilizadas na linguagem padrão (XATARA, 1998) e se percorrermos alguns dicionários específicos, logo poderemos observar que a existência de expressões similares em português do Brasil (PB), assim como em português de Portugal (PP), são frequentes. Isso nos revela a existência da necessidade dos

\footnotetext{
* Profa. Livre-Docente da UNESP/IBILCE - São José do Rio Preto

** Estagiária de Iniciação científica da UNESP/IBILCE/Curso de Tradutor - São José do Rio Preto
} 
falantes de se referirem a uma mesma situação por meio de criações figuradas e pitorescas diversas.

É certo, porém, que essas expressões consideradas similares ou sinônimas não recobrem completamente o sentido uma da outra, elas não apresentam exatamente a mesma intersecção, o que é confirmado pelo fato de que tais expressões não são intercambiáveis em todos os contextos, obedecendo às mesmas condições de uso, mantendo o mesmo valor expressivo (intensivo/eufemístico, melhorativo/pejorativo etc), ou o mesmo nível de linguagem (culto, coloquial, vulgar etc). Dessa forma, seria mais pertinente qualificar essas expressões sinônimas como "parassinônimas", o que decidimos não fazer uma vez que nos estudos linguísticos o termo mais amplamente utilizado é "sinônimo", apesar das possibilidades de variação.

Quando se trata da relação do sentido de uma EI e o sentido do que a constitui, percebemos que essa não é sempre uma relação arbitrária e pode então ser motivada por uma metáfora conceitual subjacente. Temos, portanto, a origem de um culturema.

Os culturemas estão na base da criação idiomática e geralmente apresentam uma complexidade simbólica por apresentar mais expressividade estética - pelo uso original dos recursos linguísticos disponíveis - e argumentativa - por vezes a intenção é de apresentar, de forma persuasiva, aquilo em que se acredita através do uso de recursos discursivos.

Adotamos o conceito de culturema proposto por Pamies Bertrán (2008) como símbolos extralinguísticos culturalmente motivados, a matéria-prima para que as diversas línguas produzam suas UFs. De acordo com o autor:

Os culturemas são símbolos extralinguísticos culturalmente motivados que servem de modelo para que as línguas gerem expressões figuradas, inicialmente como alusões ou reaproveitamento de dito simbolismo, e que podem se generalizar e até se automatizar. Uma vez dentro da língua como palavras ou componentes de frasemas, conservam, ainda assim, algo de sua "autonomia" inicial, na medida em que unem conjuntos de metáforas, e até permitem a adição de outras a partir do mesmo valor, acessíveis para a competência metafórica. (PAMIES BERTRÁN, 2008, p. 54)

Dessa forma, os culturemas são o resultado da condensação de elementos que formam, ao longo do tempo, metáforas consideradas aceitas como tradicionais por um povo em particular, ou por povos num sentido mais amplo. Essas metáforas criadas pelos culturemas acabam por ultrapassar o nível simbólico e se concretizam nos fraseologismos.

Cada povo utiliza seu repertório de imagens para manifestar em determinada estrutura léxica conceitos específicos, sendo as imagens, uma ponte conceitual entre a estrutura léxica e 
seu significado real (DOBROVOL'SKIJ, PIIRAINEN, 2005). Assim, muitos dos fenômenos que aparecem na linguagem figurada somente podem ser descritos de forma correta se recorrermos a códigos culturais, como crenças religiosas, costumes, literatura, artes etc (LUQUE DURÁN, 2010).

Propusemo-nos, então, a distinguir as principais experiências históricas, religiosas e culturais (LUQUE NADAL, 2009) de brasileiros e portugueses, experiências que se tornaram símbolos extralinguísticos motivados, que serviram e ainda servem de modelo para que as línguas produzam expressões figuradas lexicalizadas, e, frequentemente, expressões que se equivalem.

Por vezes, a sinonímia observada provém de culturemas semelhantes - universais fraseológicos; por outras, podemos atestar similaridade de expressões provindas de culturemas diferentes - especificidade da cultura nacional de cada povo (BARÁNOV, DOBROVOL'SKIJ, 2009).

Porém, provocadas por culturemas semelhantes ou não, as EIs sinônimas não são entre si senão pseudoequivalentes (DOBROVOL'SKIJ, PIIRAINEN, 2005), uma vez que não se trata de equivalentes semânticos e/ou pragmáticos absolutos, ou seja, não encontramos nas EIs consideradas sinônimas estruturas sintáticas e lexicais idênticas, metáforas idênticas e funcionalidade idêntica.

As semelhanças que ocorrem no interior das EIs, que compreende sobretudo os dados culturais, são explicadas pela globalização, que promove contatos interlinguísticos entre diferentes culturas, propiciando a troca desses dados culturais entre as diversas sociedades, ou seja, de suas visões de mundo, ideologias e escalas de valores.

Quando detectamos sinonímia entre as EIs do PB e PP, podemos observar que se trata de culturemas supranacionais, aqueles que são compartilhados pelos dois povos. Os culturemas supranacionais são, em sua maior parte, os culturemas mais universais, ou seja, que provêm dos símbolos criados pela mitologia, pela Bíblia e pela literatura clássica. Um exemplo de tal culturema é a imagem de Judas, que, para as civilizações cristãs, expressa símbolo de traição, deslealdade. Tais civilizações criam UFs como Judas kiss em inglês, beso de Judas em espanhol, bacio di Giuda em italiano, "beijo de Judas" em português e baiser de Judas em francês.

No caso de detectarmos EIs exclusivas, seja ao PB como ao PP, trata-se de culturemas nacionais - específicos do Brasil ou de Portugal, como por exemplo o samba, uma dança e um 
ritmo próprio do Brasil, que é transformado em culturema por representar um feito que alimenta a expressão de sedução, de malandragem, como "dar samba", com o sentido de sair-se bem em algo, em algum projeto, concretizar um objetivo. Em outras línguas não encontramos uma EI que possa recorrer a tal culturema, recorríamos, talvez, a outras imagens, a paráfrases, ou ainda, um léxico mais simples.

Por fim, não podemos deixar de mencionar a própria existência intralinguística de sinonímia entre as EIs, tradicionalmente consideradas cristalizadas e, portanto, não vulneráveis à variação. $\mathrm{O}$ fato se explica por uma cristalização ou estabilidade apenas relativa, o que deixa margem a uma variabilidade, ainda que restrita.

\section{Metodologia de trabalho}

Conforme dito inicialmente, trabalhamos com as entradas em PB e em PP do Dicionário de expressões idiomáticas português do Brasil e de Portugal - francês da França, da Bélgica e do Canadá - DEIPF - (XATARA, 2013) e nossa pesquisa orientou-se pelo método descritivoanalítico. Levantamos as EIs sinônimas por meio de uma análise descritiva das entradas em PB e seus equivalentes em PP frequentes no DEIPF e as observações se sustentaram pelo método comparativo para classificar as EIs equivalentes e por uma análise semântica centrada na cultura para se identificar os culturemas.

Em seguida, buscamos os equivalentes das EIs que apresentavam uma rede sinonímica de pelo menos três equivalentes em PB e PP. Esses sinônimos revelam uma motivação cultural diversa e não apenas variação lexical - mudança de apenas um elemento do mesmo paradigma, como em "coração de gelo" e "coração de pedra" - ou morfossintática - variação quanto à ausência ou presença de artigos e preposições como em "a dar com (o, um) pau".

\section{Resultados e Análise}

Como resultados de nossas buscas, podemos, então, verificar que de um universo de 1500 verbetes, 135 revelam entradas com ao menos três sinônimos com variante cultural, ou seja, ao menos três sinônimos em PB que vão além de simples alterações lexicais. Em relação ao PP, são 184 casos de EIs que apresentam no mínimo três sinônimos motivados por culturemas diversos.

Apresentamos as listagens dessa rede sinonímica no apêndice, logo após as Referências Bibliográficas. 
Após esse primeiro levantamento de todas as EIs em PB e em PP que trazem o mínimo de três sinônimos culturais, analisamos os principais culturemas motivadores de tais EIs. Dessa forma, detectamos os culturemas nacionais (específicos ao Brasil ou a Portugal) - que geraram EIs similares quanto ao significado mas com formulações diversas -, e também detectamos culturemas supranacionais (comuns ao Brasil e a Portugal) - que geraram as EIs idênticas em PB e em PP.

Como exemplo, selecionamos EIs que falam todas da morte em PB e em PP. Assim, as expressões usuais no Brasil:

bater as botas, entregar a alma, esticar as canelas, ir para o céu, ir (ou "passar") passar desta para a melhor, perder a vida, voltar ao pó

são igualmente encontradas em Portugal, às vezes com alguma variação lexical - "bater as botas" é usual em território português normalmente no singular: "bater a bota"; e "as canelas" de "esticar as canelas" sofre uma alteração paradigmática: "esticar o pernil” em Portugal; "ir para o céu", por sua vez, também altera "céu" em PP para "anjinhos".

Essa sinonímia intercontinental é possível porque, independente de se tratar da mesma língua, ambas as culturas, a brasileira e a portuguesa, inspiraram-se nas mesmas imagens culturais para se referir à morte: na antiga tradição de preparação dos defuntos na qual estes eram calçados com botas; na crença na existência da alma; no enrijecimento do corpo quando morto; na crença na continuação da vida para as boas almas em outra dimensão espiritual muito benéfica ou nas palavras bíblicas em que Deus criou o homem usando o barro e a esse barro o corpo volta após a morte, virando pó. Estamos diante, portanto, de culturemas supranacionais.

No entanto, para o mesmo tema, morte, também encontramos EIs motivadas por culturemas nacionais, que revelam universos culturais peculiares apenas ao Brasil ou apenas a Portugal:

\begin{tabular}{|l|l|}
\hline \multicolumn{1}{|c|}{ PB } & PP \\
\hline bater a caçoleta & dar o berro \\
comer capim (grama) pela raiz & ir para a quinta das tabuletas \\
descer ao túmulo & ir para o maneta \\
vestir o pijama de madeira & \\
virar presunto & \\
\hline
\end{tabular}


Observando essas outras EIs, todas sinônimas entre si, chegamos a distinguir algumas imagens culturais que só são utilizadas em PB, como a alusão ao tombo de alguém já morto em "bater a caçoleta", a referência à imagem daquele que é enterrado e, figurativamente, pode comer esse tipo de gramínea por debaixo da terra em "comer capim (grama) pela raiz"; menção ao local de enterro em "descer ao túmulo" ou a menção metafórica do caixão em "vestir o pijama de madeira" e a referência à carne de um cadáver humano em "virar presunto" (expressão emprestada do jargão policial para a língua comum). Da mesma forma, também distinguimos algumas imagens culturais que só são utilizadas em PP, como o grito que representa o último esforço que se faz antes de morrer em "dar o berro", a quinta das tabuletas que é uma alegoria ao cemitério em "ir para a quinta das tabuletas", a figura histórico-lendária do general apelidado "maneta", que aterrorizava a população na época das invasões francesas em Portugal, na EI “ir para o maneta”.

\section{Os culturemas mais produtivos}

Seguimos procurando desvendar quais foram os cinco culturemas brasileiros mais produtivos em EIs e seus equivalentes portugueses.

Partindo da tabela abaixo, onde reunimos sinônimos nacionais e supranacionais, teceremos alguns comentários acerca da motivação cultural dessa sinonímia:

\begin{tabular}{|c|c|}
\hline EIs em $\mathbf{P B}$ & EIs em PP \\
\hline $\begin{array}{l}\text { 1 } \\
\text { aguentar a barra, o repuxo, o tranco, as } \\
\text { pontas, o rojão / segurar as pontas, a onda } \\
\text { aguentar a mão } \\
\text { não deixar a peteca cair } \\
\text { enfrentar a parada }\end{array}$ & $\begin{array}{l}\text { aguentar / segurar a barra / as pontas } \\
\text { aguentar o tranco } \\
\text { equilibrar o barco }\end{array}$ \\
\hline $\begin{array}{l}2 \\
\text { cair / dar o fora }\end{array}$ & cair / dar o fora \\
\hline
\end{tabular}




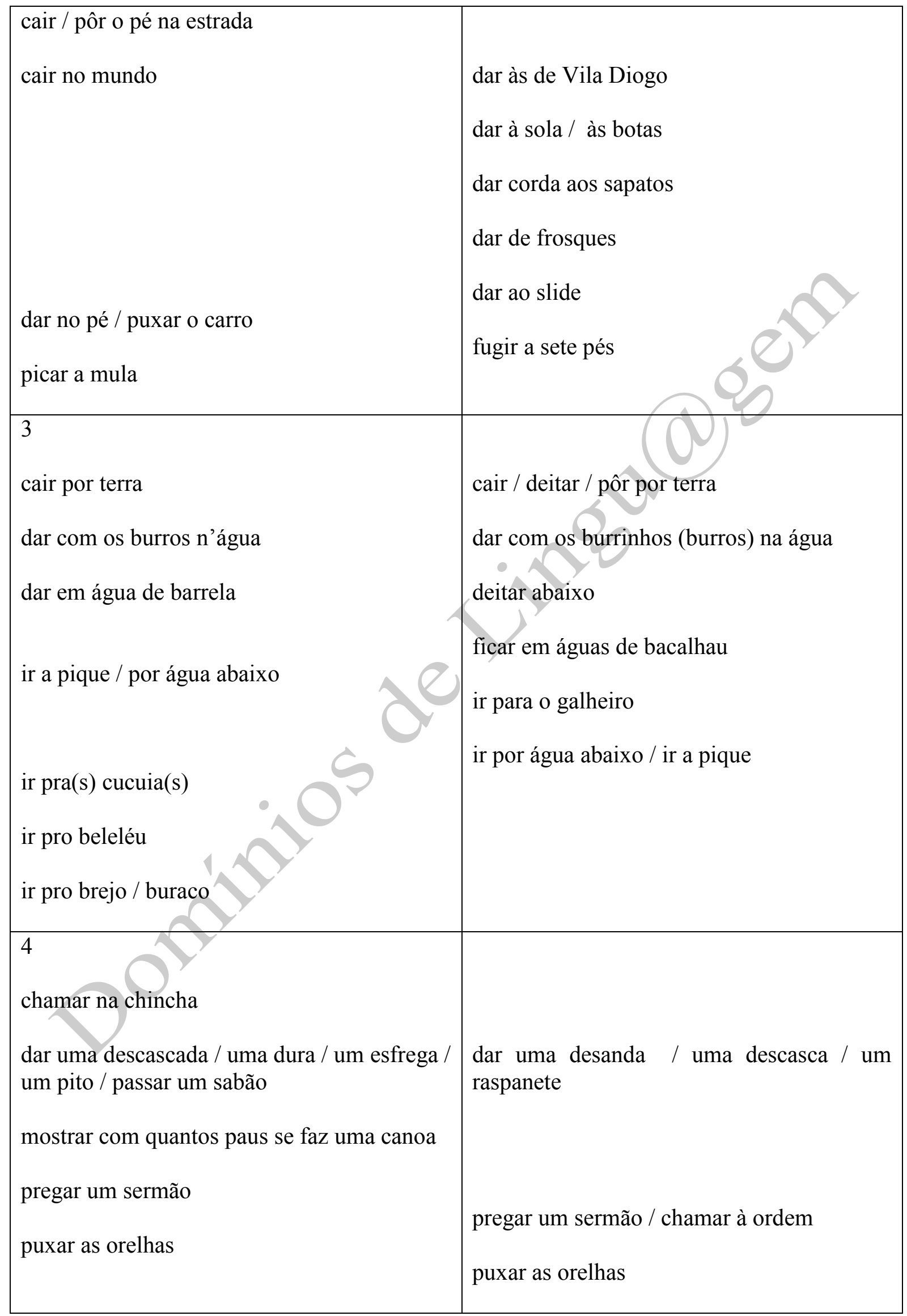




\begin{tabular}{|l|l|}
\hline na lama & na lama \\
na lona & \\
na pindaíba & na sarjeta \\
na pior & no sufoco \\
na sarjeta & no rua da amargura do poço \\
no sufoco & na mó de baixo \\
na rua da amargura & \\
no fundo do poço & \\
\hline
\end{tabular}

Em (1) temos as EIs que fazem alusão a maneira resistente de se enfrentar uma situação difícil. Primeiramente, podemos notar a ocorrência de culturema supranacional para a EI "aguentar a barra", que sofre apenas variação lexical nas duas línguas. Tais EIs simbolizam a dificuldade por meio de palavras como "barra", analogia a algo pesado; "onda", referência à força do mar; "repuxo", movimento contrário; "ponta”, uma forma que machuca. Porém, podemos notar também a ocorrência de culturema nacional, sendo específico da cultura brasileira as EIs "aguentar a mão", em que "mão" representa um símbolo de resistência e força; "não deixar a peteca cair", fazendo referência ao jogo de peteca e a perseverança de se manter a peteca no ar, o que simboliza a dificuldade; e ainda, "enfrentar a parada", gíria que indica enfrentar um momento complicado. Já a cultura portuguesa produz a EI “equilibrar o barco", em que "barco" representa uma situação difícil e que se deve saber equilibrá-la, assim como se equilibra um barco.

Em (2), vemos EIs que representam a saída de algum local, ou até mesmo a fuga. Observamos a ocorrência de culturema supranacional apenas na primeira EI, "cair / dar o fora", em que ocorre exatamente a mesma variação lexical nas duas línguas. Aqui, o culturema compartilhado pelas duas culturas é o sentido de movimento em direção à saída por meio da palavra "fora". Em seguida, notamos algumas EIs exclusivas ao PB como "cair / pôr o pé na estrada", a palavra "estrada" representando uma via que possibilita o acesso a novos lugares; “cair no mundo", fazendo referência à possibilidade de partir em direção a "novos horizontes"; 
“dar no pé / puxar o carro", em que "pé” relaciona-se a uma das partes do corpo usada para a locomoção e "carro" a um meio de transporte utilizado para se locomover; e "picar a mula", que recorre à imagem daquele que, montado em uma mula, bate sua espora contra os flancos do animal para fazê-lo andar ou correr. Temos, por fim, algumas EIs específicas ao PP e a visão de mundo dos portugueses, como "dar às de Vila Diogo", faz referência aos judeus que habitavam fora de Vila Diogo e para lá fugiam, pois nesse local tinham o direito de não serem perseguidos; "dar à sola / às botas", em que "sola" e "botas" se relacionam ao sapato, o que sugere que se pode ir a outro lugar simplesmente andando; "fugir a sete pés", em que "sete pés" alude ao fato de se correr muito rápido, como se houvesse sete ao invés de dois pés; "dar corda nos sapatos", alusão aos brinquedos que, ao se dar corda, andam rapidamente; "dar de frosques", que indica "fugir" (ressaltando que a palavra "frosques" é usada apenas na locução); e "dar ao slide", em que a palavra "slide", com o sentido de deslizar, escorregar, alude também ao ato de fugir.

Em (3), podemos observar uma maior ocorrência de motivações culturais compartilhadas, ou seja, uma maior ocorrência de culturemas supranacionais. Temos então, "cair por terra", com variação lexical em PP. A palavra "terra" é constantemente utilizada para aludir a falência, o fracasso, a derrota; “dar com os burros n'água”, com variação lexical "burros / burrinhos" em PP, provém de um conto popular sobre o fracasso de dois tropeiros que perdem toda a carga de sal e algodão ao atravessarem um rio, na disputa por uma bonificação; "ir a pique / por água abaixo", mesma variação lexical em PB e PP e alude ao movimento de navios que naufragam. Porém, observamos também EIs motivadas por imagens exclusivamente da cultura brasileira como em "dar em água de barrela", sendo "barrela" a água suja que resulta de roupas colocadas de molho para limpar e é a essa imagem explorada para se dizer que o resultado não está claro; "ir pra cucuia", "cucuia" como sinônimo de falta de sorte; "ir pro beleléu", sendo "beleléu" uma palavra de origem banta que serve para designar o lugar para onde vão os mortos; e "ir pro brejo / buraco", fazendo alusão a um local pantanoso, difícil de sair. Observamos por fim, EIs motivadas por imagens exclusivas à cultura portuguesa, como "ficar em águas de bacalhau", referindo-se à faina de bacalhoeiros que ficavam presos nessas águas e não conseguiam mais sair; "deitar abaixo", referindo-se a derrubar; e "ir para o galheiro", "galheiro", uma fogueira de galhos ou ramos, a locução alude a imagem de ir para fogueira e, por consequência, não mais escapar. 
Em (4), iniciando pelas EIs motivadas por culturemas supranacionais, temos em PB “dar uma descascada" com as seguintes variações "uma dura / um esfrega / um pito / passar um sabão", e em PP, as seguintes sinonímias “dar uma desanda / uma descasca / um raspanete; todas as variações lexicais, tanto em PB quanto em PP, apontam para o mesmo culturema, referir-se a um ato de repreensão, um ato severo, firme, para se chamar a atenção por algo. Temos ainda "pregar um sermão", sinônimo em PP de "chamar à ordem", referindo-se ao discurso moral religioso, à pregação, chamar a atenção por algo. E por fim, "puxar as orelhas”, referente ao ato denotativo de castigar as crianças. Para tais EIs, observamos mais duas sinonímias motivadas por culturemas nacionais, exclusivos à cultura brasileira, "chamar na chincha", "chincha" sendo uma pequena rede de arrastão e a locução faz alusão a imagem do pescador que traz a presa até si; e "mostrar com quantos paus se faz uma canoa", referindo-se ao conhecimento que se deve ter para uma atividade, alude ao potencialde um indivíduo de ensinar algo a outro.

Em (5), seguindo a ordem, comecemos pelas EIs motivadas por culturemas supranacionais, visões de mundo compartilhadas pelas duas línguas, temos "na lama", referindo-se à mistura viscosa e pegajosa aludindo a penúria de se estar em uma crise financeira; "na sarjeta", referindo-se aos indivíduos que vivem miseravelmente pelas ruas das cidades; "no sufoco", designando uma situação penosa, de intensa pressão; "na rua da amargura", relacionando-se ao sabor amargo para designar aquele que vive um momento difícil; e "no fundo do poço", um local escuro, fundo e de difícil acesso, procura indicar uma dificuldade extrema. As outras EIs sinônimas são motivadas exclusivamente pela cultura brasileira, como "na lona", aludindo ao ato de cair na lona do ringue quando um lutador perde a luta; "na pindaíba", gíria que significa pobreza, penúria; e "na pior", referindo-se a uma posição pouco confortável. E um registro de EI motivada exclusivamente pela cultura portuguesa, "na mó de baixo", em que "mó" significa "maior" e alude ao fato de se estar em grande dificuldade.

\section{Considerações finais}

Em geral, com o presente trabalho foi possível observar o exercício macro e microestrutural que entra em jogo na elaboração fraseográfica de um dicionário.

Pudemos determinar os principais culturemas nacionais, presentes exclusivamente nas expressões brasileiras ou lusitanas, assim como os principais culturemas supranacionais, compartilhados pelos idiomatismos do Brasil e de Portugal, podendo, dessa forma, afirmar que 
culturemas diversos acarretam uma diferença significativa na formulação fraseológica das EIs, pois cada povo usa seu repertório de imagens para manifestar em determinada estrutura léxica conceitos específicos.

Em particular, estudamos o fenômeno da variação linguística das EIs, podendo desmistificar o pretenso caráter fixo destas, uma vez que o trabalho teve um maior foco em contrastar as EIs variantes dentro de um mesmo idioma, além de levantar a sinonímia existente entre EIs do PB e do PP.

Observamos, ainda, que para justificar a sinonímia é bastante esclarecedor detectar, em primeiro lugar, os culturemas que geram as equivalências intra e interlinguisticamente.

\section{Referências Bibliográficas}

BARÁNOV, A., DOBROVOL'SKIj, D. Aspectos teóricos da fraseoloxía. Santiago de Compostela: Xunta de Galicia, 2009.

DOBROVOL'SKIJ, D., PIIRAINEN, E. Figurative language cross-cultural and crosslinguistic perspectives. Amsterdam, etc.: Elsevier, 2005.

LUQUE DURÁN, J. D. Bases teóricas del dicionário intercultural. In: CRIDA ÁLVAREZ, C.A. (ed.). Fraseo-Paremiología e Interculturalidad. 2010. 21-34.

LUQUE NADAL, L. Los culturemas: ¿unidades lingüísticas, ideológicas o culturales?, Language Design, 11: 93-120, 2009.

PAMIES BERTRÁN, A. Productividad freseológica y competencia metafórica (inter)cultural, Paremia 17: 41-57, 2008.

XATARA, C. A tradução para o francês de expressões idiomáticas em português. Araraquara, 1998. Tese (Doutorado em Linguística) - FCL, Universidade Estadual Paulista.

XATARA, C. Dicionário de expressões idiomáticas português do Brasil e de Portugal francês da França, da Bélgica e do Canadá. São José do Rio Preto: UNESP, Univ. Paris 13, Univ. Livre de Bruxelas, 2013. Disponível em www.deipf.ibilce.unesp.br

\section{APÊNDICE}

\section{Sinonímia intralinguística em PB $\rightarrow$ EIs de ao menos três sinônimos com variante cultural}

à beça / aos borbotões / aos montes / a rodo / às pencas $\cong \mathrm{a}$ dar com (o, um) pau $\cong$ pra chuchu $\cong$ pra dar e vender $\cong$ um sem número

a coisa está feia / preta / ruça $\cong$ o mar não está pra peixe

a jato $\cong$ a toda $\cong$ a todo vapor $\cong$ com o pé na tábua $\cong$ como uma flecha / um foguete / um raio $\cong$ em dois / três

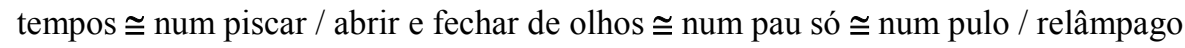


abaixar / baixar a bola [1] / a cabeça / a crista [1] @ colocar / enfiar / meter / pôr o rabo entre as pernas

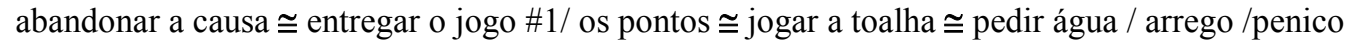
abrir a cabeça $\cong$ ter a cabeça / a mente aberta abrir a porteira / as portas / o caminho $\cong$ deixar a porta aberta

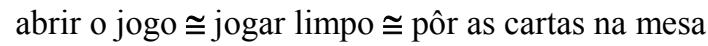
aceitar / fazer / jogar o jogo $\cong$ entrar no esquema / no jogo acender uma vela a deus e outra ao diabo $\cong$ agradar a gregos e troianos $\cong$ dar uma no cravo outra na ferradura acordar / levantar com o pé esquerdo $\cong$ acordar de ovo virado

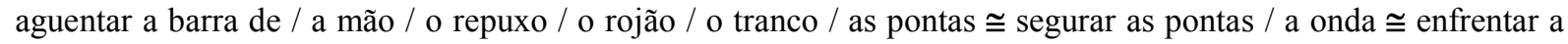
parada $\cong$ não deixar a peteca cair amarrar / fechar a cara $\cong$ fazer cara feia andar / caminhar com as próprias pernas $\cong$ voar com as próprias asas

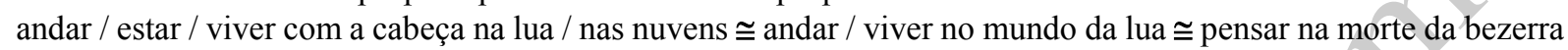

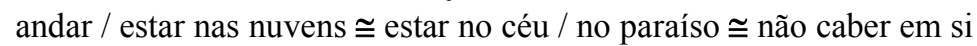

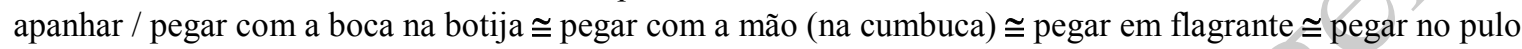
arrumar a casa $\cong$ colocar / pôr a casa em ordem até a raiz dos cabelos $\cong$ até as tampas $\cong$ até o pescoço $\cong$ até os ossos até o sabugo $\cong$ até o caroço $\cong$ até a última gota

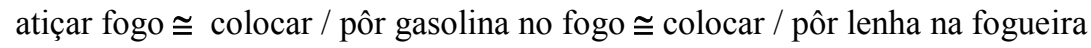
baixar o pau / o sarrafo $\cong$ descer o pau $\cong$ meter a boca / a lenha / o pau bater a caçoleta $\cong$ bater as botas $\cong$ comer capim / grama pela raiz $\cong$ descer ao túmulo $\cong$ entregar a alma $\cong$ esticar as canelas $\cong$ passar desta para a melhor $\cong$ perder a vida $\cong$ vestir o pijama de madeira $\cong$ virar o presunto $\cong$ voltar ao pó

borrar as calças $\cong$ ficar branco de medo $\cong$ tremer nas bases botar / colocar / pôr contra a parede $\cong$ encostar na parede botar / colocar / pôr o dedo na ferida $\cong$ pôr o dedo na chaga botar / colocar / pôr o pão na mesa $\cong$ ganhar o pão de cada dia botar / colocar / pôr panos quentes $\cong$ jogar água na feryura cabeça de melão / de vento $\cong$ cabeça oca cair das nuvens / de costas $\cong$ cair duro $\cong$ ficar de boca aberta cair na conversa / na onda / no conto do vigário / no laço / no logro $\cong$ ir na conversa / na onda $\cong$ morder a isca

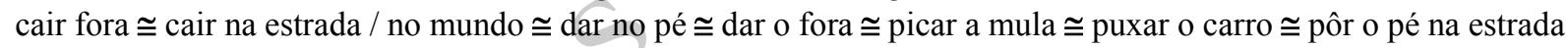
cair matando $\cong$ dar de cima $\cong$ jogar-se pra cima

cair por terra $\cong$ dar com os burros n'água $\cong$ dar em água de barrela $\cong$ ir a pique $\cong$ ir por água abaixo $\cong$ ir $\operatorname{pra}(\mathrm{s})$ cucuia(s) / pro beleléu / pro brejo / pro buraco

calar / tapar a boca $\cong$ cortar a palavra $\cong$ reduzir ao silêncio

calcanhar de Aquiles $\cong$ corda sensível $\cong$ ponto fraco

castelo de areia / de cartas / de vento $\cong$ castelo no ar

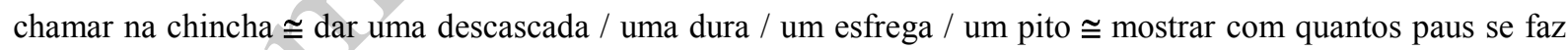
uma canoa $\cong$ passar um sabão $\cong$ pregar um sermão $\cong$ puxar as orelhas

classe $\mathrm{a} \cong$ de cinco estrelas $\cong$ de gabarito $\cong$ de marca $\cong$ de primeira categoria / linha / ordem / $\cong$ de nível $\cong$ nota 10 coçar o saco $\cong$ cruzar os braços $\cong$ ficar de papo pro ar colocar / botar / pôr o pão na massa $\cong$ ganhar o pão de cada dia

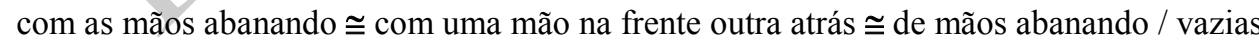
com as mãos atadas $\cong$ de mãos amarradas / atadas $\cong$ de pés e mãos atadas com o pé na cova $\cong$ às portas da morte $\cong$ em artigo de morte $\cong$ entre a vida e a morte com todas as letras $\cong$ em alto e bom som $\cong$ em português claro

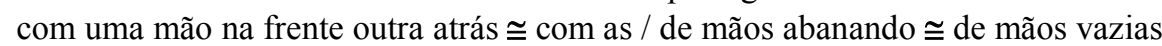
comandar / conduzir / governar o barco $\cong$ segurar ter as rédeas $\cong$ segurar o leme começar por baixo $\cong$ entrar pela janela $\cong$ entrar pela portas do fundo conversa fiada $[1] /$ mole $[1] \cong$ conversa / história pra boi dormir $\cong$ história da carochinha coração de gelo / de pedra @ coração duro

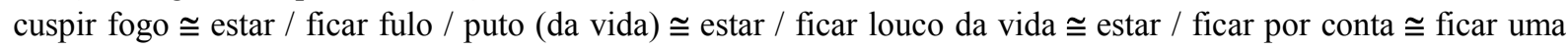
pilha $($ de nervos $) \cong$ rodar a baiana $\cong$ subir pelas paredes $[1] \cong$ subir nas tamancas 
da mesma laia / barro / estofo $\cong$ farinha do mesmo saco $\cong$ vinho da mesma pipa

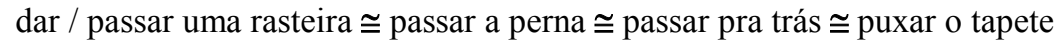

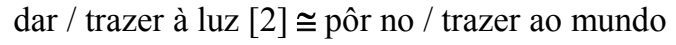
dar a última cartada / uma cartada @ queimar o (seu, um) último cartucho dar bandeira $\cong$ dar na cara / na vista $\cong$ estar na cara dar bode / chabu / crepe / galho / zebra $\cong$ entrar areia dar com a língua nos dentes $\cong$ entregar o jogo \#2 / o ouro dar nos nervos $\cong$ deixar uma pilha (de nervos) $\cong$ mexer com os nervos dar o dito pelo não dito $\cong$ dar pra trás $\cong$ roer a corda dar o troco $\cong$ pagar com a (na) mesma moeda $\cong$ responder à altura dar pitaco $\cong$ meter a colher / o bedelho / o bico / o nariz dar um basta $\cong$ dar xeque-mate $\cong$ pôr um paradeiro dar uma respirada / um tempo $\cong$ recuperar / retomar o fôlego dar uma surra / um couro $\cong$ ganhar de lavada dar-se / sair-se mal $\cong$ entrar pelo cano $\cong$ levar bomba / chumbo / ferro / tinta de baixo nível $\cong$ de meia-pataca $\cong$ de meia-tigela de bico calado $\cong$ com boca de siri $\cong$ mudo como uma pedra de cabo a rabo $\cong$ de fio a pavio $\cong$ de ponta a ponta de fininho $\cong$ de mansinho $\cong$ pé ante pé de uma hora pra outra $\cong$ de um dia pro outro $\cong$ do dia para a noite deixar / esperar a poeira abaixar / baixar / assentar $\cong$ deixar passar a onda deixar barato $\cong$ deixar por menos $\cong$ deixar pra lá descobrir a América $\cong$ descobrir / inventar a pólvora $\cong$ inventar a roda dizer com todas as letras $\cong$ não ter papas na língua $\cong$ ser curto e grosso dormir com um olho aberto e outro fechado $\cong$ dormir acordado dormir de touca $\cong$ dormir no ponto $\cong$ marcar bobeira / touca em 31 de fevereiro $\cong$ no dia de São Nunca $\cong$ quando as galinhas tiverem dentes em / sob fogo cruzado $\cong$ entre dois fogos encher a cara / a lata $\cong$ entortar o caneco $\cong$ tomar todas enciclopédia / dicionário ambulante $\cong$ enciclopédia viva $\cong$ poço de sabedoria engolir a língua $\cong$ fechar o bico $\cong$ fechar-se em copas $\cong$ guardar silêncio

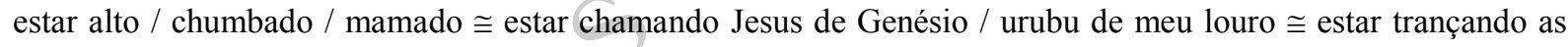
pernas

estar às portas da morte $\cong$ estar com o pé na cova $\cong$ estar em artigo de morte $\cong$ estar nas últimas / no fim estar bem arrumado / de vida $\cong$ estar com a vida feita

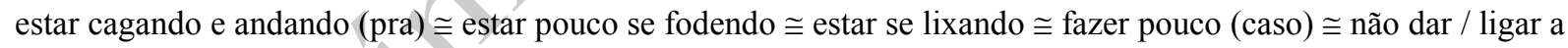
mínima $\cong$ não dar bola $\cong$ não estar nem aí estar com outra cara $\cong$ estar de cara / de roupa nova estar de alto astral / de bem com a vida $\cong$ estar pra cima estar de baixo astral / de mal com a vida $\cong$ estar pra baixo estar / ficar / cair de cama $\cong$ estar de molho estar duro / liso / quebrado[2] $\cong$ matar cachorro a grito[1] $\cong$ não ter um tostão

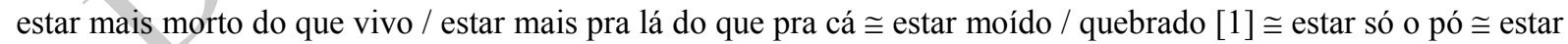
um caco/um trapo $\cong$ não se aguentar em pé estar / dar na cara $\cong$ dar na vista

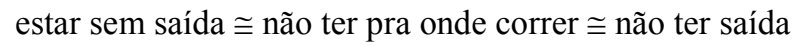
exibido como um pavão $\cong$ orgulhoso como um galo falar como uma matraca $\cong$ falar mais que a boca / que o homem da cobra $\cong$ falar pelos cotovelos fazer cara feia $\cong$ amarrar / fechar a cara $\cong$ ficar de cara amarrada / fechada / feia / virada fazer furor $\cong$ arrebentar / estourar a boca do balão feio de doer / que dói $\cong$ o cão chupando manga ficar a ver navios / chupando o dedo $\cong$ perder o bonde

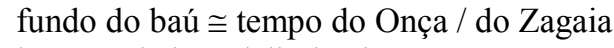
homem de bem / direito / reto 
ir longe demais $\cong$ passar da conta / da medida

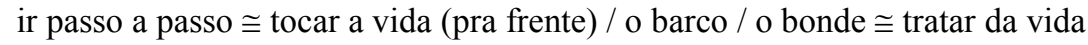
jogar no lixo $\cong$ jogar pela janela / por terra jogar pela janela / por terra $\cong$ jogar no lixo lamber as botas / a bunda / os pés $\cong$ puxar o saco

limpar a barra $\cong$ livrar a cara $\cong$ salvar a face língua afiada / comprida [2] / de cobra / ferina língua comprida [1] / de trapo / solta macaco velho $\cong$ cobra criada $\cong$ velho de guerra

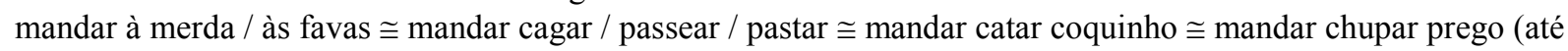
virar parafuso) $\cong$ mandar lamber sabão $\cong$ mandar pentear macacos $\cong$ mandar tomar banho (na soda (cáustica)) meter / botar / pôr a boca no trombone $\cong$ botar a boca no mundo $\cong$ gritar aos quatro cantos molhar a camisa $\cong$ dar (um) duro $\cong$ dar o / suar sangue $\cong$ fazer das tripas coração $\cong$ mover céus e terra / mundos e fundos

na lama $[1] \cong$ na lona $\cong$ na pindaíba $\cong$ na pior $\cong$ na sarjeta $\cong$ no sufoco $\cong$ na rua da amargura $\cong$ no fundo do poço na lama $[2] \cong$ na pior [2] $\cong$ no fundo do poço

não bater / regular bem $($ da bola, da cabeça $) \cong$ ter macaquinhos no sótão $\cong$ ter miolo mole $\cong$ ter um parafuso a menos

não levantar / mexer um dedo $\cong$ não mover uma palha

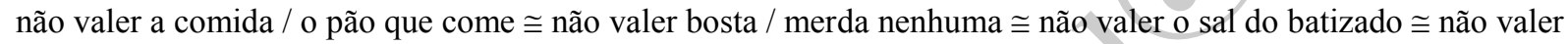
um tostão (furado)

nascer com uma estrela na testa $\cong$ nascer com a bunda / com o cu / com o rabo virado pra lua $\cong$ ser largo

no cafundó do judas $\cong$ onde judas perdeu as botas $\cong$ no cu / fim do mundo

olho clínico / vivo $\cong$ olhos de lince

seguir em frente $\cong$ tocar a vida (pra frente) / o barco / o bonde $\cong$ tocar pra frente $\cong$ tratar da vida

sono eterno $\cong$ última viagem $\cong$ último sono

ter a língua comprida / solta $\cong$ ter a língua maior que a boca

tirar o corpo fora $\cong$ tirar o time de campo $\cong$ tirar o seu da reta

\section{Sinonímia intralinguística em $\mathrm{PP} \rightarrow$ EIs de ao menos três sinônimos com variante cultural}

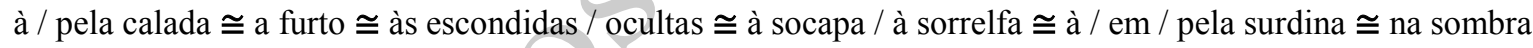

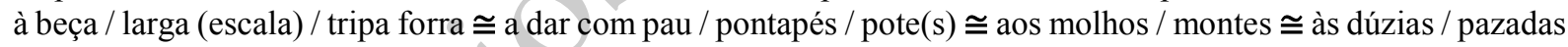
$/$ pencas $\cong$ em barda $\cong$ pra chuchu / dar e vender $\cong$ um sem número(s)

à bruta / à lei da bala / à valentona / à viva força

a céu aberto $\cong$ ao ar livre / fresco

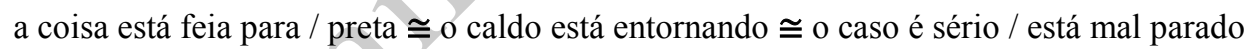

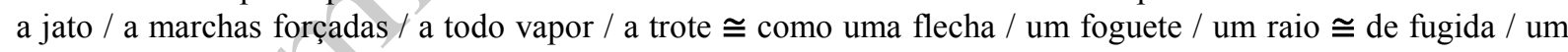
pulo / roldão $\cong$ em dois (três) tempos $\cong$ enquanto o diabo esfrega um olho $\cong$ num abrir e fechar de olhos / aí / ápice / átimo / fósforo / pronto / pulo / relâmpago @ pé na tábua

à pai adão $\cong$ em coiro / pelo / pelota (pelote)

a preço de banana $\cong$ ao preço da uva mijona $\cong$ dez réis de mel coado

abandonar a causa $\cong$ baixar os braços $\cong$ entregar o jogo / os pontos $\cong$ jogar a toalha

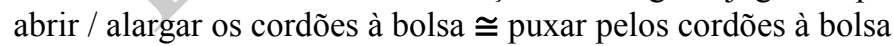

abrir a boca / o bico $\cong$ dar com a língua nos dentes

abrir as portas à / o caminho $\cong$ deixar a porta aberta

abrir o (seu) coração / a alma $\cong$ estar de peito aberto

abrir o jogo $\cong$ abrir / mostrar o jogo $\cong$ jogar limpo

aceitar / fazer / jogar o jogo $\cong$ entrar no jogo / no esquema

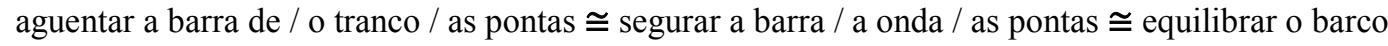

alma / coração de ouro $\cong$ coração de ouro / de pomba

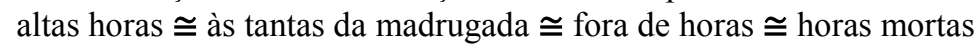

amarrar o burro $\cong$ fazer cara feia $\cong$ fechar a cara

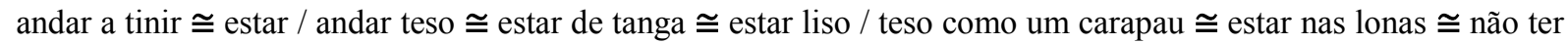

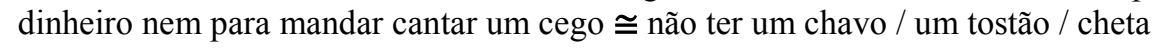


andar de casa em casa $\cong$ bater a todas as portas / de porta em porta

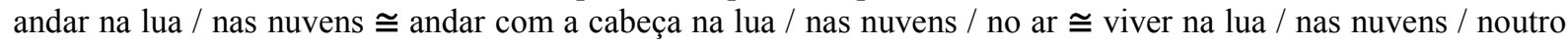
mundo

antes quebrar que torcer $\cong$ às direitas $\cong$ de palavra

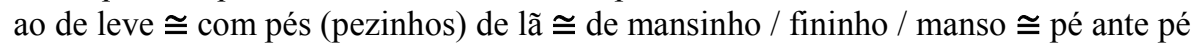

ao pé da letra $\cong$ à letra / à risca

aos quatro cantos / ventos $\cong$ pelas sete partidas do mundo

aos soluços / aos bocejos $\cong$ a conta gotas $\cong$ em doses homeopáticas

apanhar a (uma) puta / uma cardina / uma carraspana / uma de caixão à cova / uma piela / uma torta / um pifo

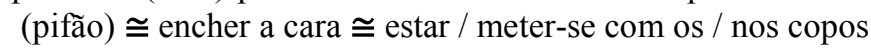

apanhar um cagaço $\cong$ tremer como varas verdes / nas bases

apregoar aos quatro ventos $\cong$ dizer à boca cheia / aos sete ventos $\cong$ gritar aos quatro ventos

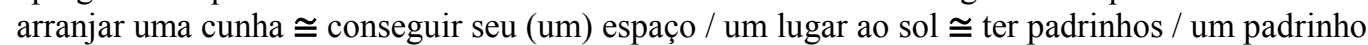

arrebentar a boca do balão $\cong$ fazer furor / ondas $\cong$ dar brado / estribilhos

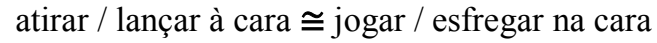

atirar à cara $\cong$ dizer as verdades $\cong$ lançar em rosto

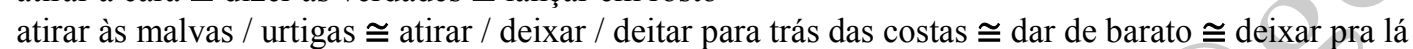

atirar-se / entrar de cabeça $\cong$ entrar a matar

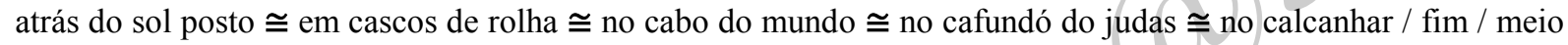

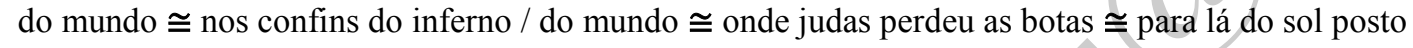

ave agoirenta / de mau agoiro $\cong$ mensageiro da desgraça

baixar a cabeça / a crista / a bola / a bolinha $\cong$ meter o rabo entre as pernas

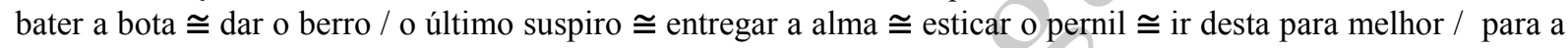

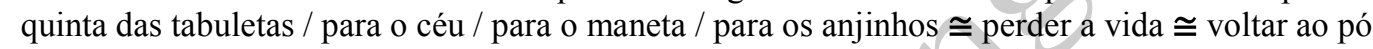

bode expiatório $\cong$ bombo da festa $\cong$ saco de pancada

cabeça de abóbora / de alho cocho / de andorinha / de atum / de burro / de vento @ cabeça no vento

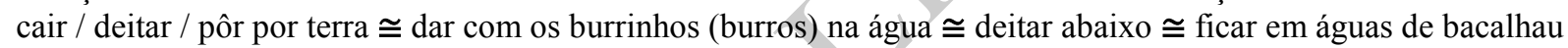

$\cong$ ir a pique / para o galheiro / por água abaixo

cair das nuvens $\cong$ ficar de boca aberta / de olhos em bico / com os olhos em bico

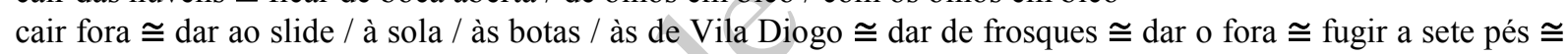
dar corda aos sapatos

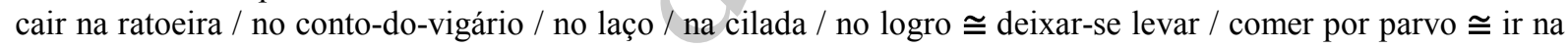
cantiga / na conversa / na onda

cair nas mãos / nas garras $\cong$ chegar às mãos

calcanhar de Aquiles $\cong$ corda sensível $\cong$ lado / ponto fraco $\cong$ telhado de vidro

cantar de galo / de poleiro $\cong$ falar grosso

cara chapada $\cong$ imagem viva de $\cong$ retrato vivo

castelo de cartas / de vidro $\cong$ castelo na areia / no ar

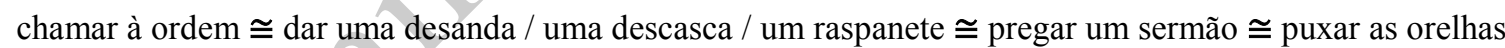

chegar a mostarda ao nariz $\cong$ deitar fumo $\cong$ estar / ficar fulo $\cong$ ferver em pouca água $\cong$ ficar às aranhas $\cong$ ficar uma pilha

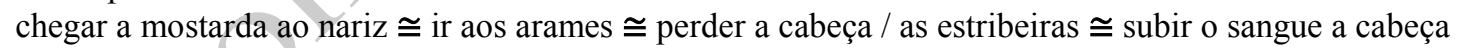

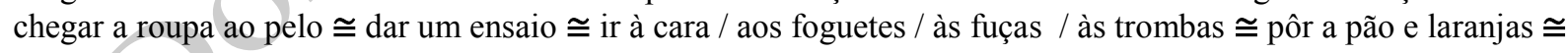
tocar a pavana

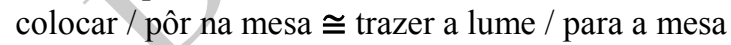

colocar o coração $\cong$ entregar-se de alma e coração / de corpo e alma

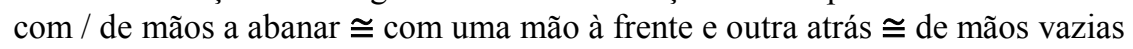

com / de mãos atadas $\cong$ de mãos e pés atados

com a cabeça erguida / levantada $\cong$ de cabeça erguida / alta / levantada

com armas e bagagens $\cong$ de mala(s) aviada(s) / mala e cuia / mala feita

com as antenas ligadas $\cong$ de antenas ligadas $\cong$ de orelha arrebitada / em pé

com uma perna às costas $\cong$ com / de olhos fechados

começar por baixo $\cong$ entrar pela janela $\cong$ entrar pela porta do cavalo / do fundo

contar com ovo no cu da galinha $\cong$ esperar por sapatos de defunto $\cong$ deitar foguetes antes da festa

conto / histórias da carochinha $\cong$ conversa de chacha $\cong$ conversa fiada / mole $\cong$ conversa pra boi dormir $\cong$ trinta

e um de boca

correr / funcionar às mil maravilhas $\cong$ correr sobre rodas 


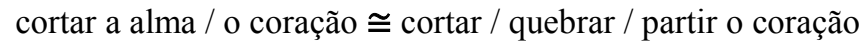

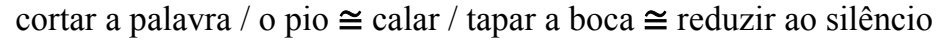

cuspido e escarrado $\cong$ como duas gotas de água $\cong$ sem tirar nem pôr

da mesma laia $\cong$ (farinha) do mesmo saco

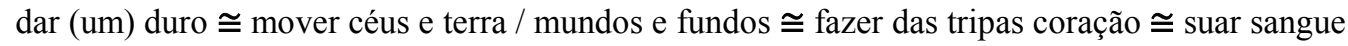

$\mathrm{dar} / \mathrm{passar} / \mathrm{pregar}$ uma rasteira $\cong$ passar a perna

dar a papinha feita $\cong$ dar de bandeja / de mão beijada

dar à(s) canela(s) / à perna / ao canelo $\cong$ dar corda aos sapatos

dar bandeira $\cong$ dar nas vistas $\cong$ estar na cara $\cong$ ser claro como água

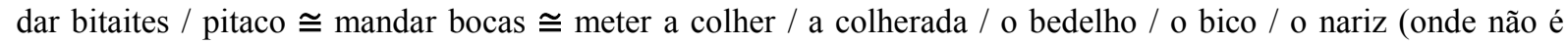

chamado) $\cong$ meter a foice em seara alheia $\cong$ meter-se onde não é chamado

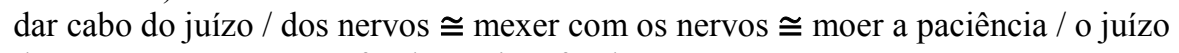

dar gás $\cong$ meter prego a fundo $\cong$ pisar fundo

dar margem $\cong$ abrir brecha / margem

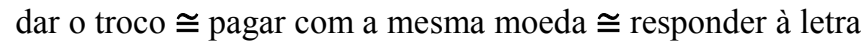

dar uma arraial de porrada $\cong$ ir às fuças / à tromba

dar uma banana $\cong$ fazer um manguito / um toma

dar uma nega / (a) tampa $\cong$ deixar pendurado

dar-se / sair-se mal $\cong$ levar chumbo

de (todo [o]) coração (aberto) $\cong$ do fundo do coração

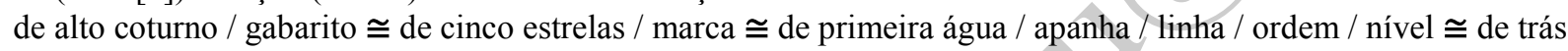
da orelha

de arrepiar os cabelos $\cong$ de deixar / pôr os cabelos em pé

de baixo nível $\cong$ de meia tigela / pataca $\cong$ de trazer para casa $\cong$ de tuta e meia

de bom coração $\cong$ de coração (bom)

de encher as medidas / o olho $\cong$ de fazer arregalar os olhos $\cong$ de tirar o fôlego

de molho $\cong$ em banho-maria $\cong$ na mesma como a lesma $\cong$ para segundas núpcias

de pernas / patas para o ar $\cong$ de pantanas

deitar / meter / pôr lenha na fogueira $\cong$ deitar achas na fogueira

deixar andar / correr o marfim $\cong$ deixar o barco correr

descobrir / inventar a pólvora $\cong$ inventar a roda

dicionário ambulante $\cong$ enciclopédia viva $\cong$ poço de sabedoria

dizer cobras e lagartos / horrores / poucas e boas / raios e coriscos $\cong$ dizer trinta por uma linha

dizer com todas as letras $\cong$ não ter papas na língua $\cong$ ser curto e grosso

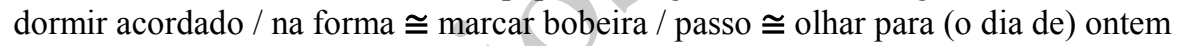

dormir com um olho aberto e outro fechado $\cong$ passar pelas brasas

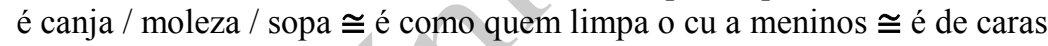

em / sob fogo cruzado $\cong$ entre dois fogos / o martelo e a bigorna

em pé de guerra $(\mathrm{com}) \cong$ estar em brasa $(\mathrm{com}) \cong$ estar bera

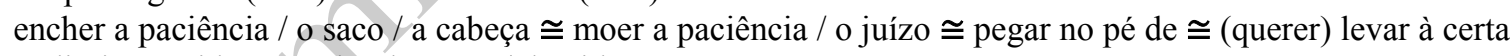

endireitar a vida $\cong$ mudar de rumo / de vida

entrar a matar/de caras $\cong$ ser duro

entregue às moscas / às traças $\cong$ no rol dos esquecidos

erguer / levantar a cabeça $\cong$ meter ombros

esquentar a cabeça $\cong$ deitar as mãos à cabeça $\cong$ ficar à nora

estar / ficar atravessado na garganta $\cong$ ficar entalado na garganta

estar / ficar de olho $\cong$ ficar de atalaia

estar / sentir-se como peixe n'água $\cong$ estar no seu elemento

estar / ter no sangue $\cong$ estar na massa do sangue

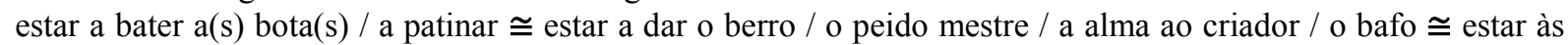

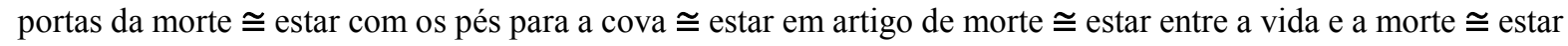
mais para lá do que para cá $\cong$ estar nas últimas

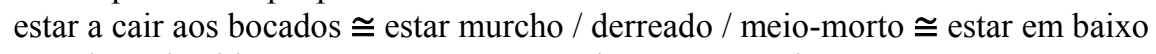

estar bem de vida $\cong$ estar nas suas sete quintas $\cong$ ter muito caroço

estar cheio de genica $\cong$ estar com a corda / a pica toda

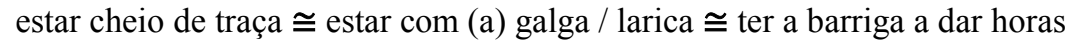

estar com a pica toda $\cong$ estar de bem com a vida / de alto astral 
estar elétrico $\cong$ estar em brasa / em frango

estar na direção / no caminho certo $\cong$ estar no bom caminho

estar nas nuvens / no céu / no paraíso $\cong$ estar nas suas sete quintas

estar num dia mau / não $\cong$ não estar nos seus dias

estar por um fio / um triz $\cong$ estar / ser por uma unha negra

falar / bradar / pregar no deserto $\cong$ pregar aos peixes

fazer bonito / um figurão / um vistão $\cong$ botar figura

fazer orelhas moucas $\cong$ fazer ouvidos de mercador / moucos

fazer ouvidos de mercador $\cong$ fechar / tapar os ouvidos

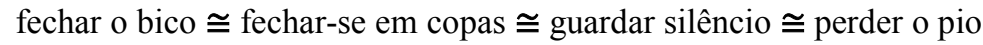

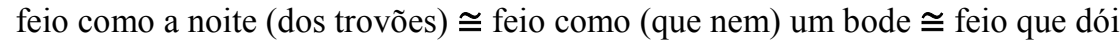

ficar com cara de parvo $\cong$ ficar com um grande melão $\cong$ ficar de cara à banda

ficar de papo pro ar $\cong$ coçar os tomates $\cong$ cruzar os braços

ficar ela por ela $\cong$ responder na mesma moeda $\cong$ sem ela por ela

ficar na mó de cima / por cima $\cong$ levar a melhor

fogo de palha / de vista $\cong$ sol de pouca dura

fome canina / negra $\cong$ fome de leão / de lobo / de rabo

ir ao leme $\cong$ mexer os cordelinhos $\cong$ ter as rédeas

ir longe de mais $\cong$ passar da conta / das marcas

jogar / deitar no lixo $\cong$ deitar fora $\cong$ jogar / deitar pela janela $\cong$ jogar por terra

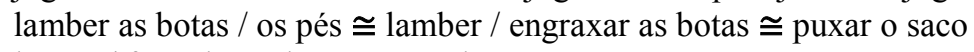

lançar / fazer luz sobre $\cong$ trazer luz

levar / ter às costas $\cong$ carregar nas costas

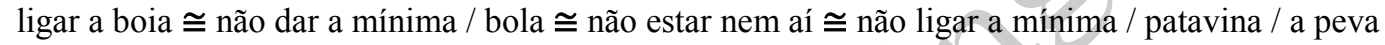

mandar bitaites / bocas $\cong$ dizer bocas

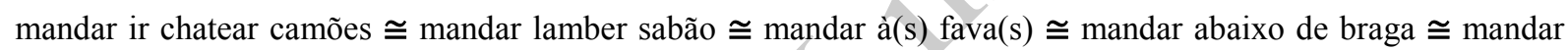

bugiar / passear / pastar $\cong$ mandar pentear macacos

matar / quebrar a cabeça $\cong$ puxar pela cabeça $\cong$ dar voltas ao miolo

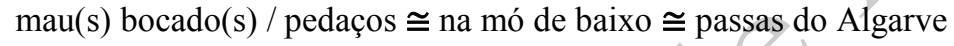

meter / pôr as mãos $\cong$ fazer mão baixa

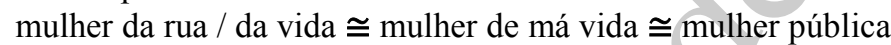

na bruta / marra $\cong$ a ferro $\cong$ à viva força

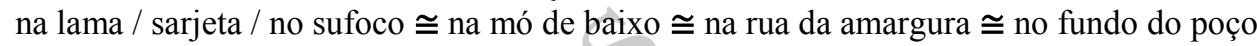

não (nem) aquecer nem arrefecer $\cong$ tanto se me faz como se me fez $\cong$ tanto se me dá como se me deu

não bater / regular bem $($ da cabeça $) \cong$ não bater bem (da cabeça $) /$ da bola $\cong$ não ser bom da cabeça $\cong$ ter pancada

(na bola) $\cong$ ter um parafuso a menos

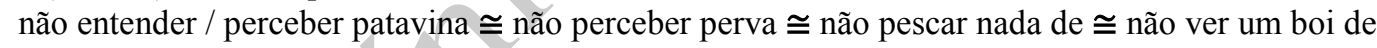

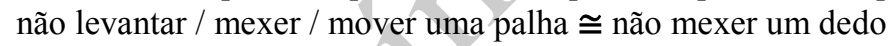

nascer sob uma (boa) estrela $\cong$ nascer (com a bunda, com o cu, com o rabo) virado para lua

nos trinques $\cong$ novo (novinho) em folha $\cong$ num brinquinho

ouro de lei $\cong$ de ouro $\cong$ ouro sobre azul

partir a cara / as fuças $\cong$ ir / partir ao, o focinho

perder o fio da / à meada $\cong$ perder o fio ao discurso

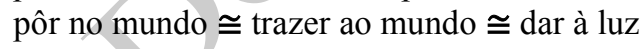

por uma unha negra $\cong$ por um fio / um triz

rebentar a rir $\cong$ rebolar(-se) de riso $\cong$ rir à(s) bandeira despregadas $\cong$ rir como um perdido

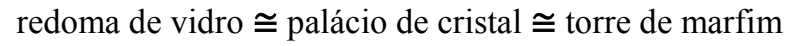

saber da poda / do (seu) ofício $\cong$ saber o que a casa gasta

seguir em frente $\cong$ tocar a vida / o barco $\cong$ tratar da vida

sem mais nem menos $\cong$ sem dizer água vai $\cong$ sem mais aquelas $\cong$ sem mais nem porquê

ser um troca-tintas / um vira-casacas $\cong$ virar a casaca

sono eterno $\cong$ última viagem / último sono

sossegar o facho $\cong$ tomar rumo $\cong$ tomar tino

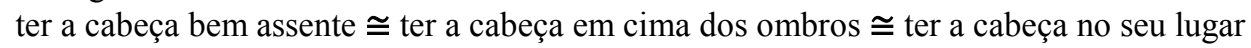

trazer / chamar à baila $\cong$ trazer à colação / ao terreiro

último grito (da moda) / última moda / palavra $\cong$ na berra

verdade nua e crua / verdadeira $\cong$ verdade verdadinha 


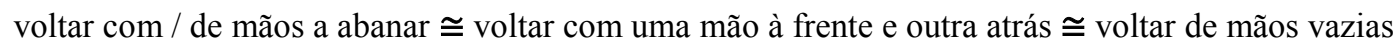

Artigo recebido em: 20.02.2014

Artigo aprovado em: 16.05.2014 